\title{
Slow potential topography
}

\author{
HERBERT BAUER \\ University of Vienna, Vienna, Austria
}

\begin{abstract}
Several studies analyzing slow and long-lasting changes in scalp-recorded brain potentials have recently been published (e.g., Vitouch, Bauer, Gittler, M. Leodolter, \& U. Leodolter, 1997). Such long-lasting changes turned out to be applicable as a fairly direct measure of cortical activity. Combined with multichannel recording, slow potential recording can serve as a data source for a noninvasive functional topography in cognitive psychophysiology. This paper describes methodological aspects crucial for true DC recording. Special properties of this brain activity signal will be addressed in the light of its complex origin. Since DC-EEG topography appears to be very promising for future research, specific aspects of multichannel DC-EEG handling, data processing, imaging, and analysis are specifically discussed. Finally, the advantages that cognitive psychophysiology may gain from DC-EEG topography are addressed.
\end{abstract}

The terms slow potential (SP), slow potential shift (SPS), and DC-potential (DC-P) are commonly used to unspecifically cover a wide variety of slow potential changes in the EEG that are evoked by single and multiple informational stimuli or that precede overt and covert intentional behavior. For example, these terms are used for endogenous components of the event-related potential (ERP), such as the $\mathrm{P} 200, \mathrm{P} 300$, the processing negativity or the $\mathrm{N} 400$, and so on, as well as for the "contingent negative variation" (CNV) and the "readiness potential" (RP) (for a comprehensive review, see, e.g., Rockstroh, Elbert, Canavan, Lutzenberger, \& Birbaumer, 1989).

The present paper will deal with scalp-recorded brain potential changes that accompany temporally extended cognitive processing. Such potential changes may also be categorized as SPs, SPSs, or DC-Ps, but, in contrast to the endogenous ERP components that are linked to stimulus anticipation and evaluation and to response preparation and generation, they are intimately related to the core cognitive processes under investigation. In this sense, these potential changes probably fit exactly what Caton (1875) meant when he stated, "When any part of the grey matter is in a state of functional activity, its electrical current voltage usually exhibits negative variation." Caton observed sensory-evoked DC potentials, which may also serve here as an example to illustrate the difference (see Figure 1): In this case, a simple tone lasting for $2 \mathrm{sec}$ evokes quite complex potential changes, an on-effect (i.e., an ERP with all its components reflecting stimulus evaluation), an off-effect (i.e., essentially, a simple ERP but with slightly smaller amplitudes than those of the oneffect), and the DC component between them, which lasts for the entire duration of the stimulus and therefore ac-

Correspondence should be addressed to H. Bauer, Institute of Psychology, University of Vienna, Liebiggasse 5, A-1010 Vienna, Austria (e-mail: herbert.bauer@univie.ac.at). companies a simple but temporally extended cognitive process (i.e., in this case, hearing a tone).

Since Caton's first report, several results have been published that support a close correlation between enhanced multiunit activity and negative-going slow potential changes. Rebert (1973) observed a striking similarity between the time course of the synchronously recorded integrated multiunit activity and the negative-going DC-P in the lateral geniculate of the cat during temporally extended flash stimulation. Very similar results have been observed with intra-/epi-cortical recordings by Rosen and Stamm (1969), Stamm and Rosen (1972), Caspers (1974), Fuster (1978), Speckmann, Caspers, and Elger (1984), Caspers, Speckmann, and Lehmenkühler (1984), and Roitbak, Fanardjian, D. S. Melkonyan, and A. A. Melkonyan (1987).

By recording slow potential changes relative to a starting point (baseline), using sufficiently high spatial resolution, and by mapping the amplitudes using proper interpolation techniques, the continuously changing cortical activity distribution can be monitored. This procedure has been referred to as slow potential topography (SPT). As is also the case with other techniques, there are, of course, several restrictions of a biological, physical, and technical origin to be taken into account, which will be addressed and discussed later in this paper. However, one limitation needs to be mentioned right away: the restriction due to the gyral structure of the cerebral cortex. Because of this special geometry, the generators that are basically oriented perpendicular to the cortical surface project to the outer cortical envelope (dura) in a very complex manner, and they probably initiate additional radially oriented ionic currents within the sulci. This complex spatial orientation of the generators results in a subdural potential distribution that, without any additional information, necessarily leads to a reduced spatial resolution. A further reduction of the spatial resolution that can, however, be controlled to a considerable extent originates from vol- 


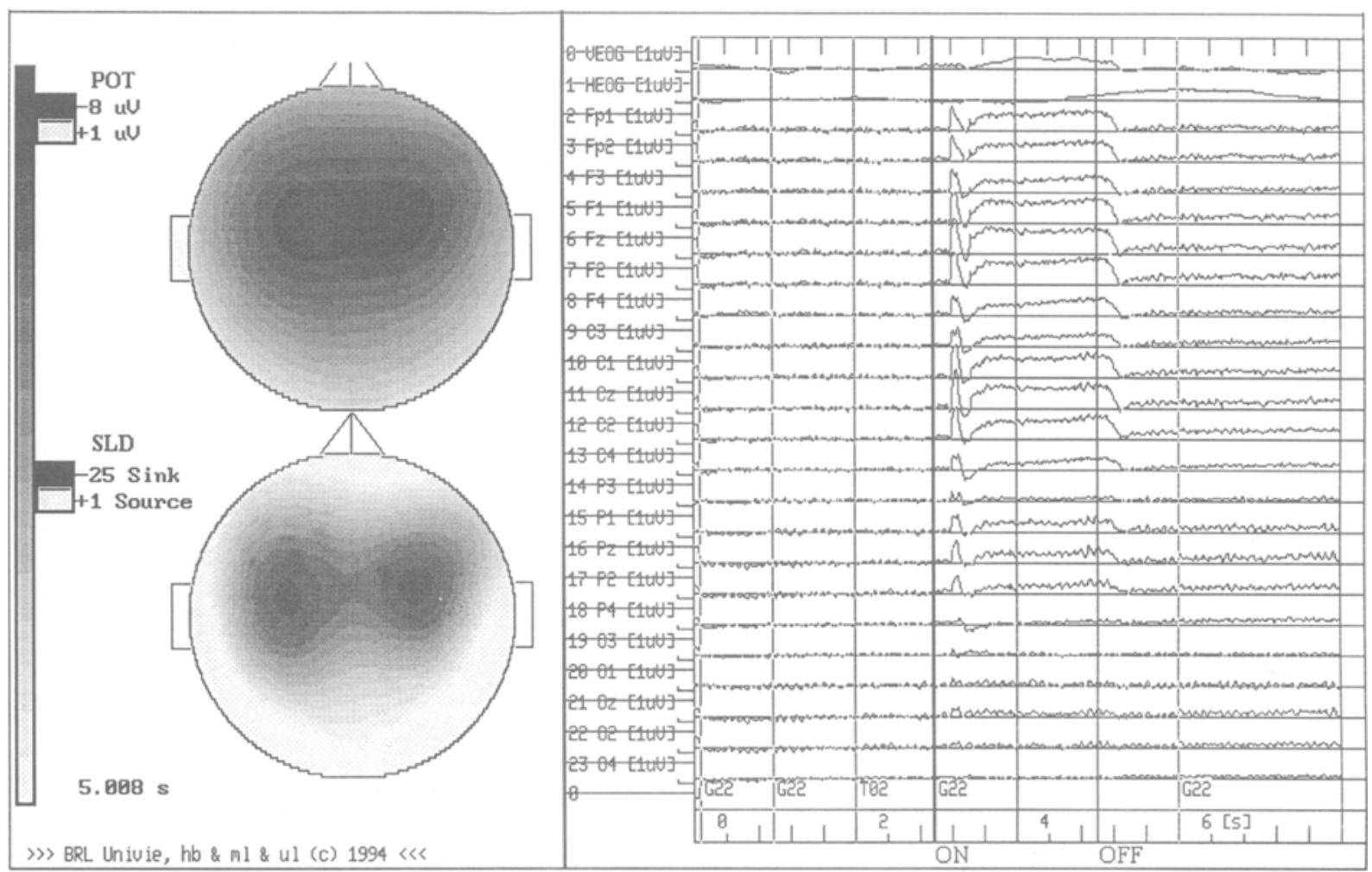

Figure 1. Averaged DC-ERP with simple tones (800-Hz sine wave, $65 \mathrm{~dB}$ SPL, 2 sec in duration). Left: Single-latency SP (top) and SLD (bottom) maps exactly at the end of the stimulus. The scalp Laplace derivation (SLD) map may here be taken as a display with enhanced spatial resolution showing bilateral activity foci corresponding to activity in the auditory cortical areas. Details on SLD-map construction are given in the text. Right: Multichannel display of the DC-ERPs.

ume conduction through the various layers of tissue up to the scalp (see below).

\section{On the Origin of Slow Potential Changes}

Scalp-recorded brain potentials and their slow changes originate from extracellular ionic currents within the brain tissue. These currents are maintained by the ionic concentration and potential gradients that exhibit a tendency toward reduction. Active neurons within a particular cortical area generate these ionic concentrations and the resultant potential changes (for details see reviews by, e.g., Speckmann et al., 1984, and Vaughan \& Arezzo, 1988). Additionally, tonic shifts (in a range of minutes) can be observed that are closely related to stimulus- or processinglinked phasic shifts (usually in the seconds range). Negative SPSs that accompany information processing decline slowly after processing stops. If consecutive processing trials start before trial-specific initial baselines have been reached (which usually takes several seconds), new phasic shifts are added; in this way, they produce the tonic change. This has been shown by Bauer, Korunka, and M. Leodolter (1993), using a CNV paradigm and, recently, by means of topographic representation during spatial processing (Vitouch, Bauer, Gittler, M. Leodolter, \& U. Leodolter, 1997). Figure 2 shows consecutive maps of SPSs that accompanied spatial processing of $13-\mathrm{sec}$ median duration (varying within a range of $5 \mathrm{sec}$ to $2 \mathrm{~min}$ ) per trial. Gradually mounting slow potential changes that decrease slowly after response are obvious in occipitoright-parieto-temporal areas. It is not reasonable to assume that these long-lasting large phasic shifts, which accumulated to even larger tonic shifts over trials, reflect a gradual recruiting of more and more neurons involved in processing the tasks; instead, it most probably indicates an additional "nonneuronal" generator that becomes gradually excited with localized tonic neuronal activity.

This points to another type of brain cell that has already been taken into account with slow potential genesis. Glial cells respond to the extracellular potassium concentration in various ways according to their bioelectric membrane properties (see Kettenman, 1987; Kuffler, Nicholls, \& Orkand, 1966; Nicholson, 1980; Roitbak, 1965, 1983; Somjen \& Trachtenberg, 1979). Repetitive firing of neurons leads to a local elevation of extracellular potassium, which in turn initiates a local potassium influx into the glia. In this way, potassium becomes redistributed via the glial functional syncitium by efflux where extracellular potassium is low (Coles \& Orkand, 1983; Dietzel, Heinemann, Hofmeier, \& Lux, 1989; Sykova, 1983). Resulting extracellular ionic currents not 

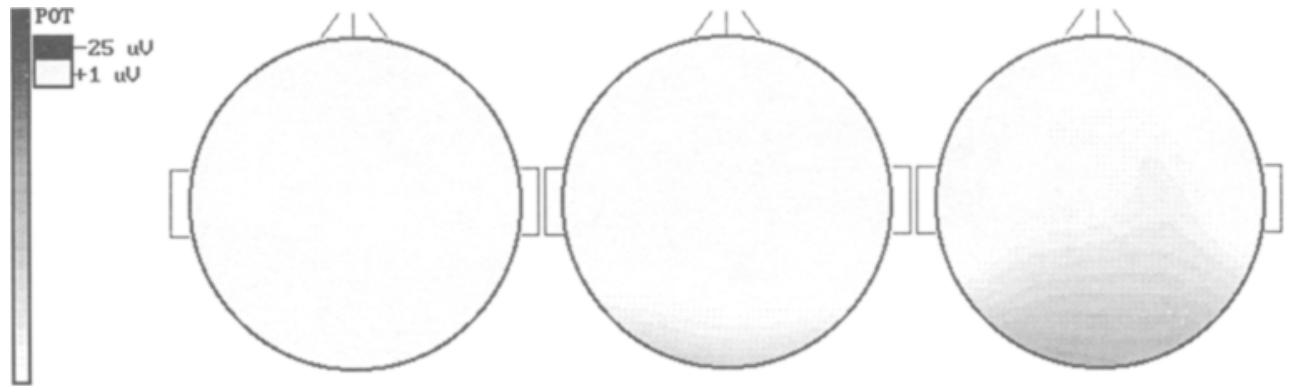

$$
\text { Stimulus } \quad+0 \mathrm{sec} \quad+1 \mathrm{sec} \quad+2 \mathrm{sec}
$$
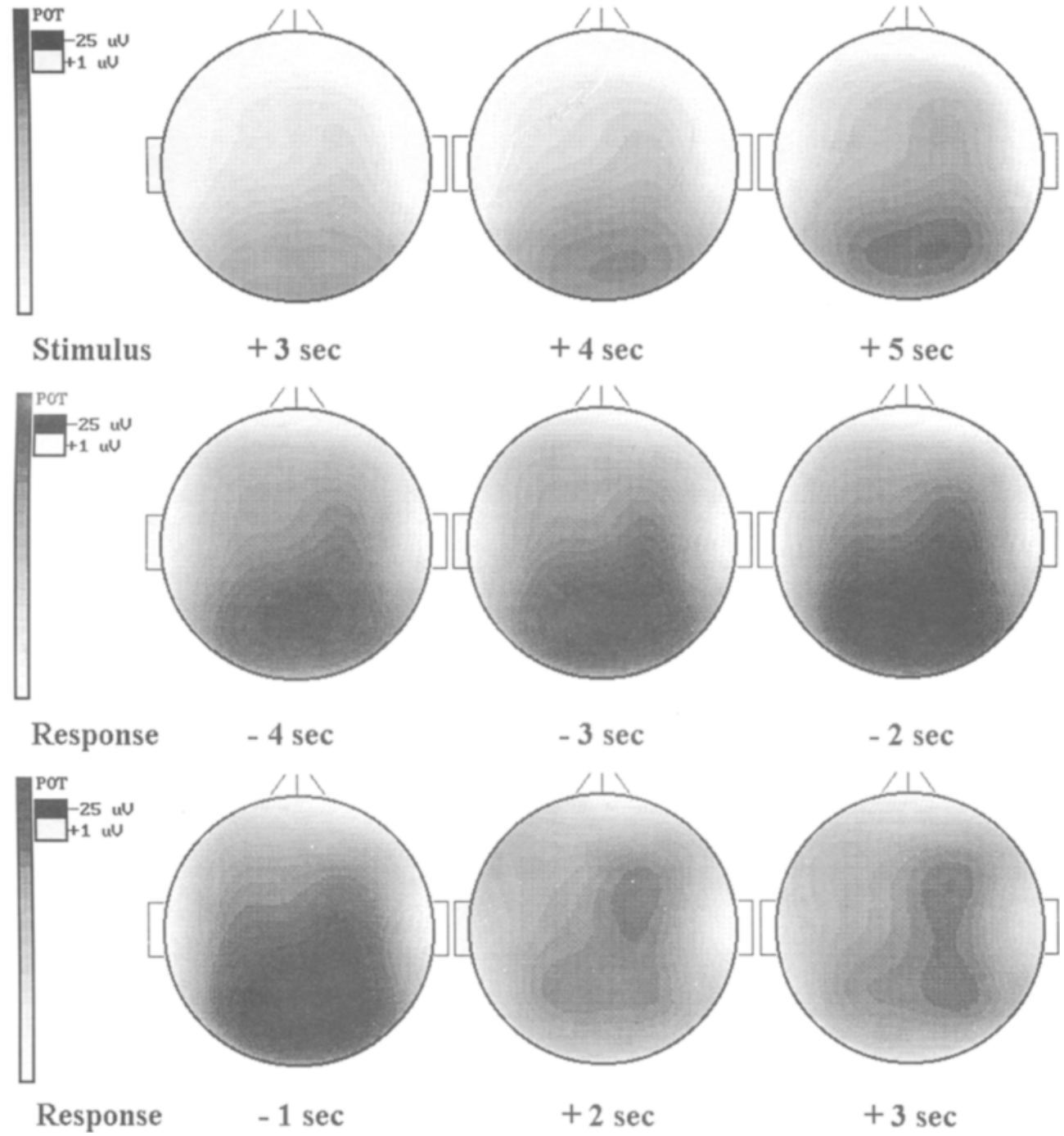

Figure 2. Maps of grand mean SPSs accompanying spatial processing $(N=400)$ with latencies of $0,1,2,3$, 4 , and 5 sec after item onset and 4,3,2, and 1 sec prior to responses, as well as 2 and 3 sec after responses. A gradual increase in local SPS amplitudes with ongoing cognitive processing can clearly be seen; amplitudes decrease slowly after responses.

only amplify neuronally generated currents but also modify them due to the different time course of glial membrane processes. To what extent local changes of the extracellular space due to glial cell swelling (Ransom, Carlini,
\& Connors, 1986; Svoboda \& Sykova, 1991; Sykova, 1987; Sykova \& Chvatal, 1993) also cause such currents has not yet been specifically investigated (Sykova, Hansson, Rönnbäck, \& Nicholson, in press). 


\section{Localization of Generators of Large Scalp-Recorded Potential Changes}

When applying concentric sphere head models, the magnitude of the scalp potential depends on the strengths and sizes of correlated dipole layers in the cortex. Such dipole layers consist of a variable number of synchronously active minicolumns within a particular cortical area. Numeric simulations by means of a three-concentric sphere model revealed scalp potential estimates of 4 and $23 \mu \mathrm{V}$ with a dipolar cortical source of $100 \mu \mathrm{V}$ but active surface areas of 4 and $40 \mathrm{~cm}^{2}$, respectively (Nunez, 1981); with subcortical locations of various depth of such dipoles, their strengths and sizes would need to be much larger (ultimately, they would reach physical limits) in order to still produce the same scalp potential values. This suggests that large scalp-recorded potential amplitudes most likely originate from cortical structures. Using a spherical four-shell model (according to Cuffin \& Cohen, 1979), Lutzenberger, Elbert, and Rockstroh (1987) also demonstrated that scalp-recorded slow potential changes with large amplitudes originate predominantly from cortical, rather than subcortical, sources.

\section{Practical Significance for \\ Cognitive Neuroscience}

Until recently, electrophysiologically oriented cognitive neuroscience focused predominantly on "pulse"evoked short-latency and short-duration cognitive processes. There are two main reasons for this focus. First, the use of ERP components to investigate cognitive processes is well established. Second, although DC recording permits the monitoring of long-lasting activities in the brain, there are some difficulties with this method that have prevented its general use in cognitive neuroscience. Alternative imaging techniques, such as PET and SPECT, have been used to investigate long-lasting or repetitive cognitive processes. This emphasis on long-lasting processes is related to the poor temporal resolution of these methods. In my opinion, the research with alternative imaging techniques has made a substantial contribution to cognitive neuroscience not so much because of the higher spatial resolution available but because, as has already been mentioned, it has necessarily focused on the investigation of temporally extended processes (for a comprehensive review, see Posner \& Raichle, 1994).

SPT, although restricted to monitoring activities of the cerebral cortex, makes comparable research possible: It is a noninvasive means for investigating complex cortical functions that potentially allows the observation of subroutines involved in a particular temporally extended cognitive process, provided that these subprocesses can be sequentially and spatially separated from each other.

Due to the gradually mounting potential changes that accompany long-lasting cortical activity (as shown in Figure 2), SPT basically offers an additional way of averaging over time. Provided the recordings are drift-free, the channelwise averaging of perhaps 30 consecutive or partly overlapping 5-sec epochs taken during sustained cognitive processing of one item (i.e., one trial) results in a multichannel DC-ERP that converts into topographical maps typical of the cognitive activity executed.

\section{Recording Aspects}

An indispensible prerequisite for SPT is a particularly high stability of the technical baseline (amplifier and electrode-scalp interface). If some channels drifted, maps would change dramatically and become uninterpretable. Bauer, Korunka, and M. Leodolter (1989) summarized the important aspects. However, some of these that directly influence baseline stability should be emphasized once more.

First, the input impedance of the amplifiers needs to be very high, since this allows currents flowing through recording electrodes to be kept very low. This current across the electrode-scalp interface is a direct current, and it therefore flows in one direction over a long period of time and would lead to a slow polarization in compartments containing freely moving ions (i.e., cutaneous tissue). When using multichannel common reference recordings - the usual setup with digital signal processing-this fact becomes even more important, because a large part of the currents will be forced across the reference electrode interface and can lead to slow unidirectional drift artifacts. On the basis of such theoretical considerations, an input impedance of $>10 \mathrm{G} \Omega$ and an input bias current of not more than $1 \mathrm{pA}$ are mandatory. Second, skin scratching (Bauer et al., 1989) is still a matter of debate, but, after more than a decade of experience with the combined use of this type of skin preparation and self-designed "clip-on" electrode adapters (see Figure 3; Bauer et al., 1989), we still recommend this procedure. There has never been any case of a complication with this procedure, and sterilization of the electrode adapters after each application guarantees hygienic standards, even more than with uncontrolled skin-abrasion techniques. Skin scratching drops and equalizes interelectrode impedance below $1 \mathrm{k} \Omega$, thus making interelectrode recording conditions more alike and significantly reducing skin potential artifacts.

Finally, it needs to be emphasized that the electrodeskin interface is highly sensitive to any mechanical influence (e.g., radial or tangential movements). Because of this, electrode caps of any type, such as the ECI cap (Electrode-Cap International, Inc.) or the geodesic sensor net (Tucker, 1993), are insufficient for DC recording and SPT, since each electrode needs to be kept in place independently.

To speed up electrode application for multichannel recording, we have developed an application kit. This kit consists of an adjustable, partly flexible plastic frame that goes around the forehead, reaches down just below the earlobes, and connects both sides at the nape of the neck. The frame is kept in place by means of a chest belt. Using Velcro, a net made of elastic bands can be fastened over the head in such a way that adapters (Bauer et al., 1989) for all electrodes can be kept in place simultane- 


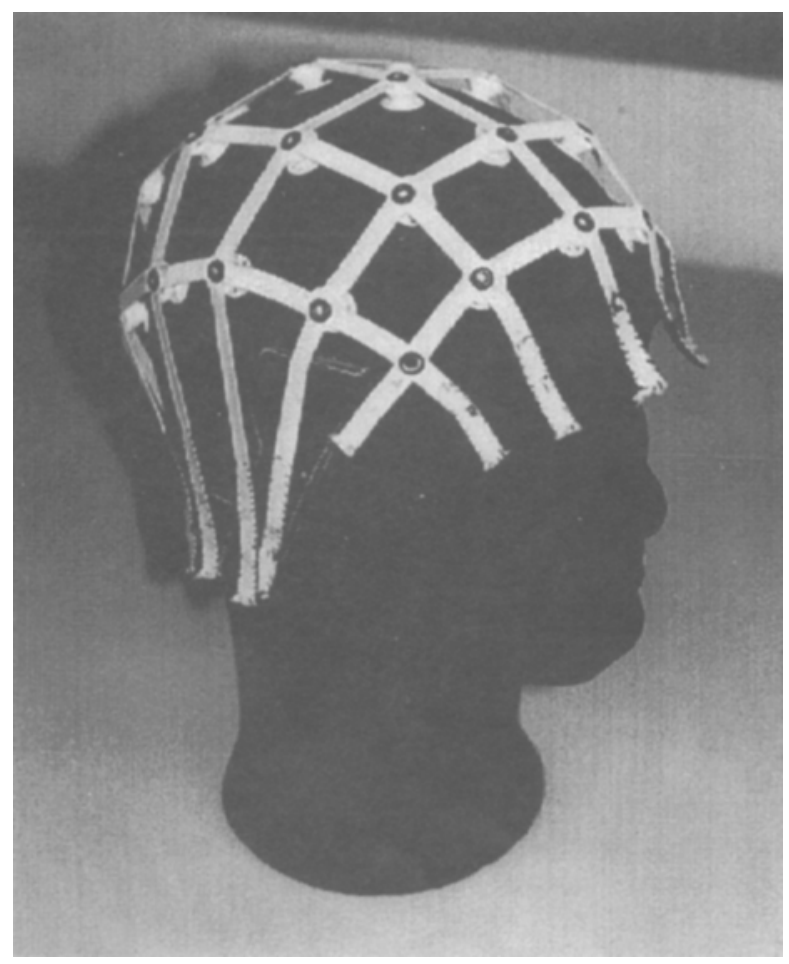

Figure 3. Electrode application cap. (For detailed description, see text.)

ously (see Figure 3). After securing all electrode adapters by collodion, the elastic net and the head frame are removed, and all adapters will be in place. Electrodes can then be clipped on after the skin has been scratched and both the electrode and the adapter have been filled with degassed gel. As we have seen in our laboratory, this procedure works efficiently with 22 electrodes but will presumably be helpful with up to 64 locations.

\section{Necessary Methodological Implementations}

Due to the volume conduction properties of the head, a spread projection of the potential distribution at the outer cortical surface (epicortical potential distribution) appears on the scalp. That means roughly that an epicortical "point activity" acts on a somewhat circular scalp area of about $2.5 \mathrm{~cm}$ in diameter (Doyle \& Gevins, 1986). Epicortical patterns thus appear on the scalp in a diffuse way and are distorted due to the complex and variable cranial geometry and the uneven distribution of skull conductance. This makes scalp potential patterns appear more alike across subjects, which in turn encourages one to calculate averages across subjects, neglecting variance in recording locations due to the different head shapes and sizes. Even if we do not actually calculate grand (group) mean signals, this is what happens whenever analyses of variance are used to statistically investigate mean differences, and we accept all this "spatial noise."
In all SPT studies published so far, statistical analyses of topographical patterns have been based on the signals at the actual recording sites, neglecting the sources of variance just mentioned. But in order to keep SPT (electroencephalography) competitive to modern functional imaging techniques, such as rCBF, PET, or fMRI, it will be necessary to compensate for all this methodologically caused noise. Just emphasizing the potentially high temporal resolution of EEG recordings is not very helpful; it is in fact questionable, since the actual temporal resolution of slow EEG components relevant for SPT is certainly not within the millisecond range.

With complex cognitive processing, we do not know precisely where in the cortex activity might occur. But even if we knew it, we would not be able to place a few electrodes exactly at the right locations because of the interindividual variance in volume conduction conditions. Only the topographically observed EEG actually captures the available information, provided spatial sampling criteria are fulfilled (see discussions by Coppola, 1990; Gevins, Brickett, Costales, Le, \& Reutter, 1990; and Gevins, Le, Brickett, Reutter, \& Desmond, 1991).

As with other imaging techniques, the actual procedure should therefore be as follows. First, global epicortical activity images need to be calculated that take each individual head shape into account. These images then need to be normalized in order to finally automatically extract data sets for statistical analysis. This might not always be possible in this ultimate consistency; a semiautomatic, visually controlled data extraction from raw images, for example, might make it possible to avoid variance of individual activity patterns that originate from the individual spatial aspects of the generating sources. In any case, we should appreciate that only thoroughly constructed epicortical activity images convey valuable and usable information.

Scanning the recent literature one finds all the relevant aspects already addressed and the groundwork accomplished - that is, spatial sampling (Coppola, 1990; Gevins, 1989, 1990; Lehmann, 1986; Srinivasan, Nunez, Tucker, Silberstein, \& Cadusch, 1996; Srinivasan, Tucker, \& Murias, 1998; Wang, Cohen, \& Hallett, 1989), ways of reducing blur distortion due to volume conduction (Gevins, 1990; Law \& Nunez, 1991; Le, Menon, \& Gevins, 1994; Nunez, 1989, 1990; Srinivasan et al., 1996), and enhancement of spatial resolution by using realistically shaped head models (Gevins, 1990; Gevins et al., 1990; Gevins et al., 1991; Gevins et al., 1994; Le \& Gevins, 1993). In order to encourage the practical application of the suggested solutions in SPT, an overview will be given below.

\section{Spatial Sampling}

Although the temporal and spatial frequencies of EEG components relevant for SPT seem to be positively correlated, the following has to be kept in mind. Unlike sam- 


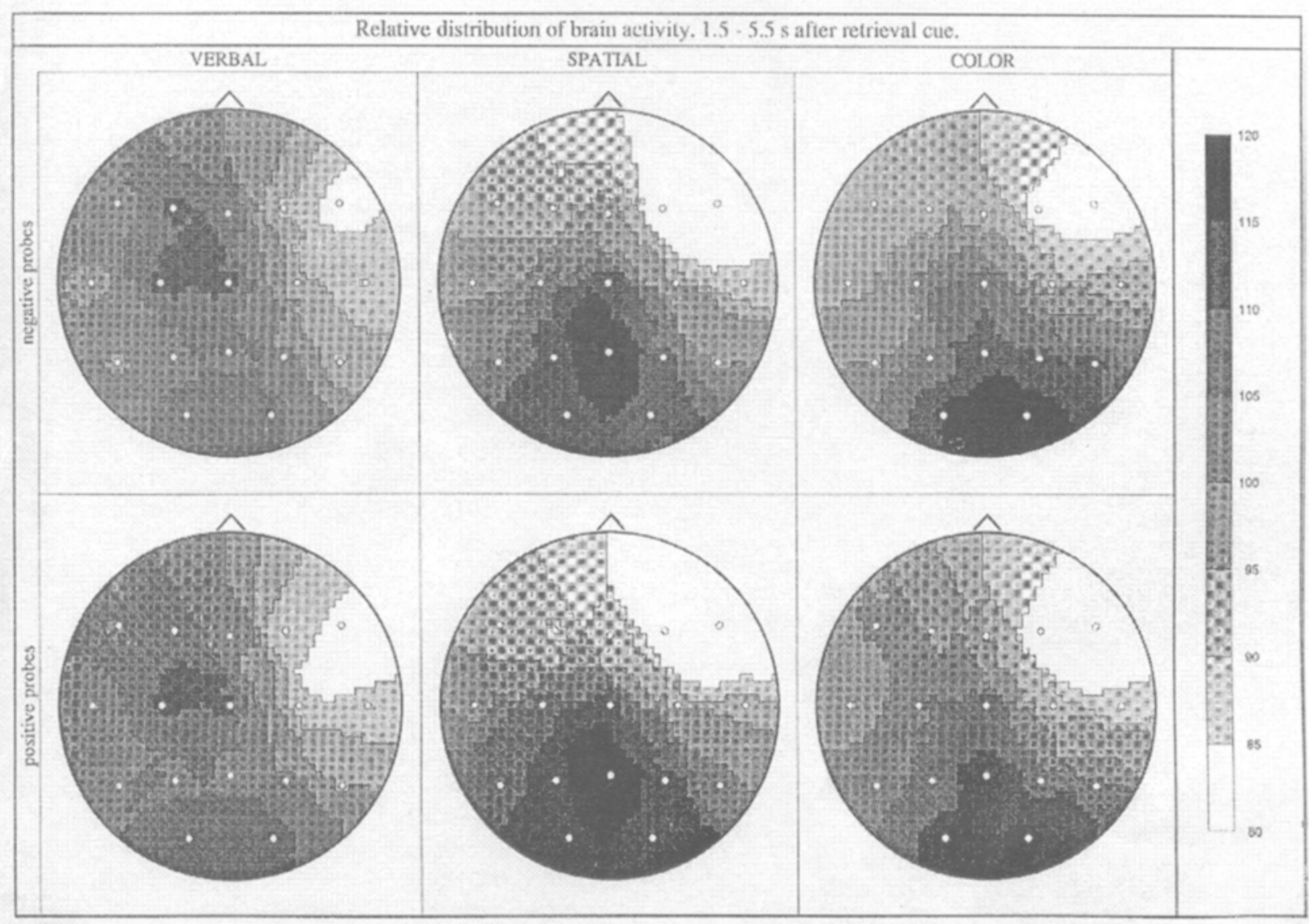

Figure 4. Standardized topographic maps of the average activity measured during a 4-sec epoch beginning 1.5 sec after item onset. Maps are given separately for negative (top; the correct response was "no") and positive (bottom row; the correct answer was "yes") and the three experimental conditions with verbal, spatial, and color associations. From "Distinct Cortical Activation Patterns During Long-Term Memory Retrieval of Verbal, Spatial and Color Information,” by F. Rösler, M. Heil, and E. Hennighausen, 1995, Journal of Cognitive Neuroscience, 7, p. 57. Copyright 1995 by MIT Press. Reprinted with permission.

pling over time, where signal conditioning by means of analog antialiasing filters is possible, adequate spatial sampling can only be achieved by placing electrodes sufficiently close together in accordance with the highest spatial frequencies that may possibly occur (i.e., there is no way of spatial antialiasing filtering prior to sampling). As has been shown by Gevins $(1989,1990)$, spacing the electrodes $2 \mathrm{~cm}$ apart is necessary in order to be sure to avoid spatial aliasing. With this spacing, more than 128 electrodes are required to cover the entire scalp surface. Employing 16, 27, and 51 electrode montages, Gevins also demonstrated that merely the correct lateralization of central activity accompanying right finger flexion demanded at least 27 electrodes (Gevins, 1990). In another example using 122 channels, Gevins et al. (1991) showed by desampling to 57,31 , and 18 channels that, although spline interpolation makes all the different maps visually appealing, it was only when all 122 channels were included that two separate activity peaks were obvious that corresponded to the tactile stimulation of the left-middle and right index fingers.

This issue is specifically addressed by Srinivasan et al. (1998). Quite generally, we need to realize that the problem of spatial sampling is basically no less stringent in SPT. Although spatial aliasing effects are attenuated in SPT due to averaging, adequate representation of steep spatial potential gradients demands montages of at least 64 electrodes.

Aside from using large array recordings (e.g., 64 channels), a stepwise approach is sometimes applicable, but certainly not ideal: In the first step, a topographical screening is carried out with electrodes evenly distributed all over the scalp to roughly localize active areas, whereas, in the next step, all the electrodes are placed within these identified active areas to achieve sufficient spatial resolution. Apart from the greater number of experiments necessary, the applicability of this approach depends on the size of the area that remains for detailed analysis, and the 

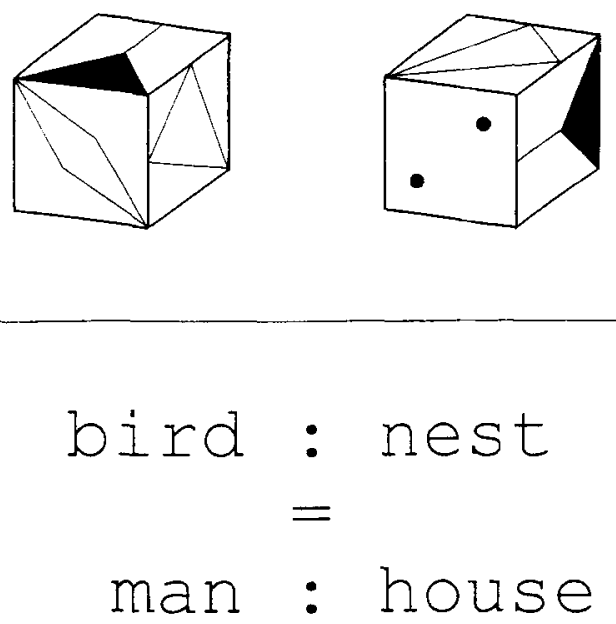

Figure 5. Sample items employed by Vitouch et al. (1997): spatial (top), verbal (bottom); the correct answer for both was "yes." From "Cortical Activity of Good and Poor Spatial Test Performers During Spatial and Verbal Processing Studied With Slow Potential Topography," by O. Vitouch, H. Bauer, G. Gittler, M. Leodolter, \& U. Leodolter, 1997, International Journal of Psychophysiology, 27, p. 187. Copyright 1997 by Elsevier Science-NL. Adapted with permission.

mapping algorithms have to take the patch-like electrode placement into account.

\section{Reduction of Blur Distortion Originating From Volume Conduction and Estimation of the Epicortical Potential Distribution}

\section{As Nunez (1990) stated,}

It has become axiomatic in EEG/ERP research that there exists no unique source distribution for any given scalp potential distribution. It is less widely appreciated that a unique relationship does exist between scalp potential and the potential on the cortical surface, provided only that there are no sources between the two surfaces.

As far as this fact is concerned, in recent years, two routes have been developed for improvement of the spatial resolution of the scalp potential distribution: the $\mathrm{ra}$ dial current estimate (RC)-also referred to as surface Laplacian derivation (SLD) (Hjort, 1975) or more frequently termed current source density (CSD) - and spatial deconvolution.

Though not a true distortion-correction method, SLD can be applied to the blurred scalp data to improve the spatial frequency resolution and eliminate the common activity at all electrodes. There are basically two approaches: One is referred to as local, and the other is referred to as global.

Hjort's second-order finite difference procedure, the classic local approach, assumes a planar scalp surface, and it was based on a rectangular electrode montage because it simplified calculations. This original scheme has been improved on, resulting in the "nearest neighbor" SLD still based on a planar surface but calculating an average of the directional derivatives from each sur- rounding electrode to the given electrode (Hjort, 1980; Katznelson, 1981; Nunez, 1981; Thickbroom, Mastaglia, Carroll, \& Davies, 1984). Le et al.'s (1994) implementation of the SLD method takes the nonplanar scalp surface into account. With this implementation, first, the actual three-dimensional (3-D) contour of the subject's scalp surface is reconstructed from a given set of (actually measured) spatial electrode coordinates. Second, for any electrode, the local scalp surface that includes the surrounding electrodes is identified. Third, the local potential distribution function is approximated by means of a local spectral interpolation function using the potential values at the electrodes selected. Then, the Laplacian value is estimated within a planar parametric space associated with the identified 3-D local scalp surface, using a set of potential values generated by the local spectral interpolation function through Taylor expansion and the least squares procedure.

With the other (i.e., global) approach, a global interpolation function is first estimated, and then the Laplacian differentiation operation is applied to the global function. A frequently used algorithm is the spherical spline interpolation procedure suggested by Perrin, Bertrand, and Pernier (1987) and Perrin, Pernier, Bertrand, and Echallier (1989). With this procedure, in a first step, a spherical or ellipsoidal (e.g., Law \& Nunez, 1991) surface is approximated to the scalp surface using the spatial electrode positions. The SLD values are then calculated by suitable differentiation of the resulting interpolation function with respect to the two surface tangent coordinates (Law, Nunez, \& Wijesinghe, 1993; Nunez, 1989). In this way, a usable scalp surface model (a sphere or ellipsoid) can be created on the basis of a smaller number (perhaps 20) of electrodes evenly spaced over the whole scalp. This approach also has its drawbacks. When the electrodes are, for example, placed within a smaller region of the scalp, this produces distorted models. The global mathematical interpolation also leads to artificially higher coherence between electrodes (Biggins, Fein, Raz, \& Amir, 1991), and it is basically a questionable assumption that the higher order derivatives of the interpolation function approximate the higher order derivatives of the original potential distribution function (Fein, Raz, \& Turetsky, 1991). A comprehensive evaluation of possible interpolation errors with various mapping algorithms has recently been published by Fletcher, Kussmaul, and Mangun (1996).

In addition, and importantly, we have to keep in mind that the SLD does not take into account spatial inhomogeneity of the tissue conductivity between the outer cortical surface and the scalp (especially that of the skull). It simply produces spatial patterns similar to those that would be recorded at the bottom of a uniform and homogeneous piece of conducting material. If the conductivity profiles of the skull were available, SLDs could be corrected for this inhomogeneity and the currents radially injected into the skull could be estimated. Local skull conductivity depends on both the local conductiv- 

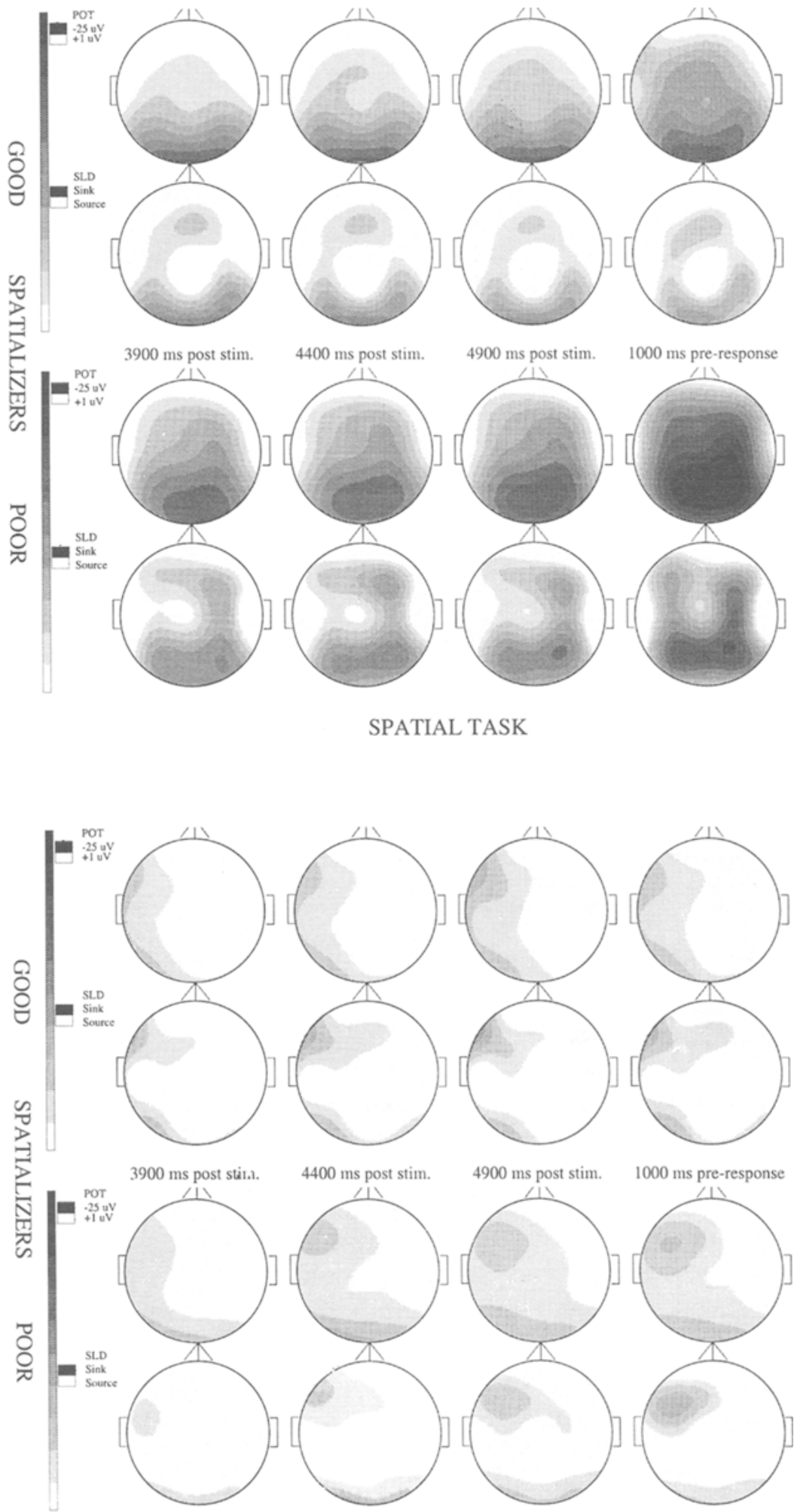

VERBAL TASK

Figure 6. SP and SLD maps at four latencies observed with spatial and verbal processing separated for good (top) and poor (bottom) spatializers. Data are from "Cortical Activity of Good and Poor Spatial Test Performers During Spatial and Verbal Processing Studied With Slow Potential Topography," by O. Vitouch, H. Bauer, G. Gittler, M. Leodolter, \& U. Leodolter, 1997, International Journal of Psychophysiology, 27, pp. 191-192, Figures 4-5. Copyright 1997 by Elsevier Science-NL. Adapted with permission. 

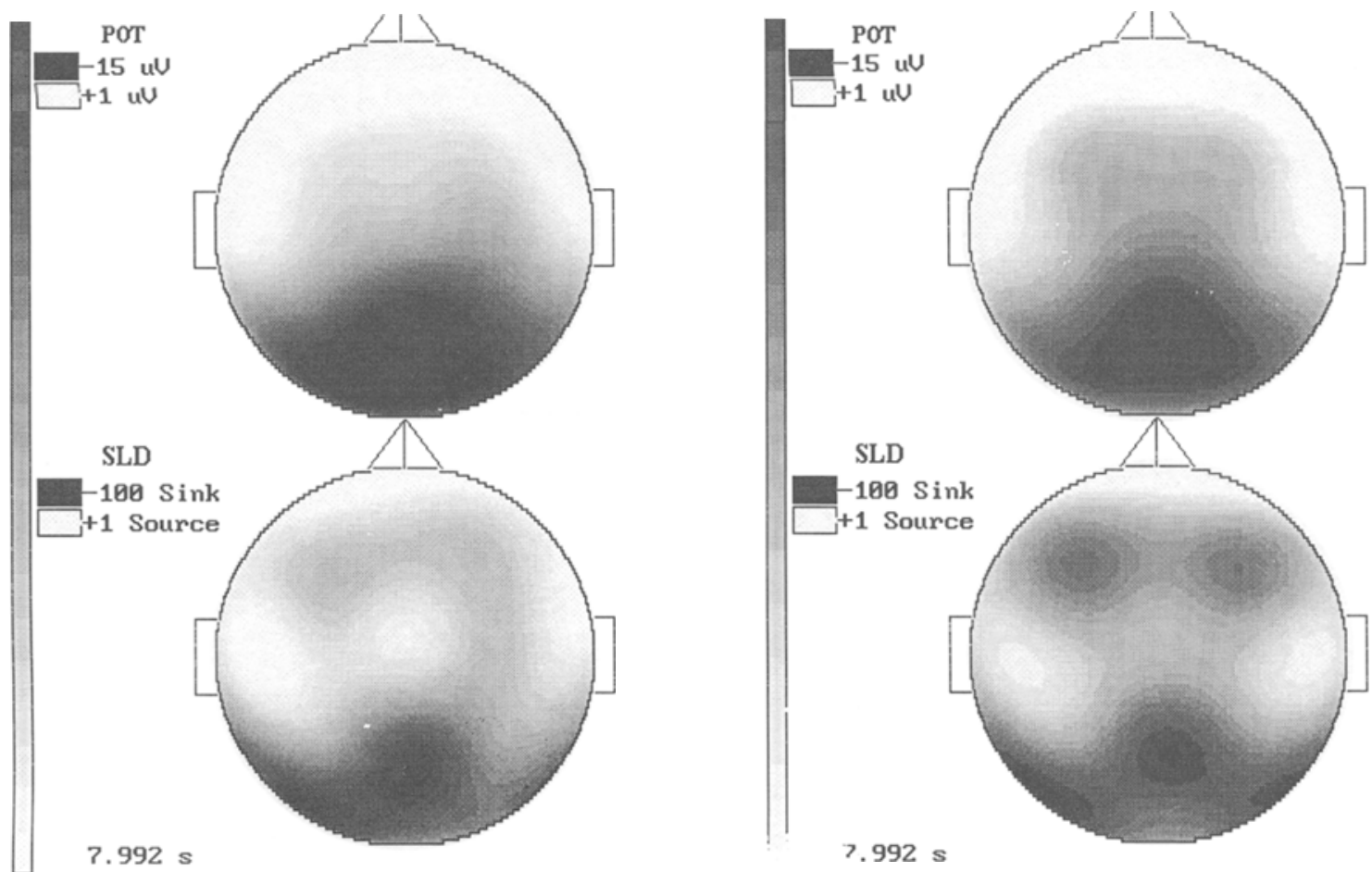

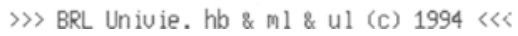

Figure 7. Effects of spatial training on SP and SLD maps. Left: pretraining. Right: posttraining; note the additional frontal activity. From Raumvorstellungstraining und langsame, ereigniskorrelierte Potentials, by C. Lamm, 1996, Vienna: University of Vienna. Copyright 1996 by C. Lamm. Reprinted with permission.

ity and the thickness of the bone. Both may vary over the cranial surface by a factor of three or more (Rush \& Driscoll, 1969; Todd, 1924). Nunez (1989) views the correction of Laplacian estimates by independently measured local skull conductivity as one long-range research goal. In his paper, which presents a method to estimate local skull resistance based on the surface potential due to a known dipole-like source using a three-concentric sphere model, he also emphasized the importance of such a correction in all procedures aiming for an improvement of spatial resolution (Nunez, 1987).

As has been mentioned, an alternative possibility to enhance the EEG's spatial resolution is the application of spatial deconvolution procedures. With this approach, explicit biophysical models of geometric and passive conducting properties of the head (e.g., a three-concentric sphere model used by Nunez, 1987) are employed to estimate the topographical distribution of potential or outgoing current density on a hypothetical epicortical sphere based on the scalp potential distribution (e.g., for planar medium, Nicolas \& Deloche, 1976, and Freeman, 1980; "cortical imaging technique, CIT," Kearfott, Sidman, Major, \& Hill, 1991).

Gevins and colleagues developed a new technique referred to as finite element model deblurring (FEMDB) that works without imposing assumptions about the actually generating cortical source locations, which is necessary with spatial deconvolution (Doyle \& Gevins, 1986; Gevins et al., 1990; Gevins et al., 1994; Le \& Gevins, 1993). On the basis of a finite element model of the conducting volume between the outer cortical surface and the scalp surface, a transformation matrix is constructed that predicts the scalp potential for any given set of cortical potentials. By means of an efficient iterative process, the cortical potential distribution can then be determined as the closest fit between its forward solution and the recorded scalp potential distribution. Since there is currently no direct measurement available for local conductivity, skull thickness combined with a conductivity constant has been used as an estimate.

This implementation is certainly the most advanced procedure, since it makes an attempt to take all (realistic) volume conduction aspects into account. This achievable improvement, however, comes at a price: MRIs with integrated electrode markers have to be recorded, and individual finite element head models based on these MRIs have to be calculated. Nevertheless, this should not discourage anyone from making use of this possibility, since computing power is now generally available and has become enormously cheaper. 

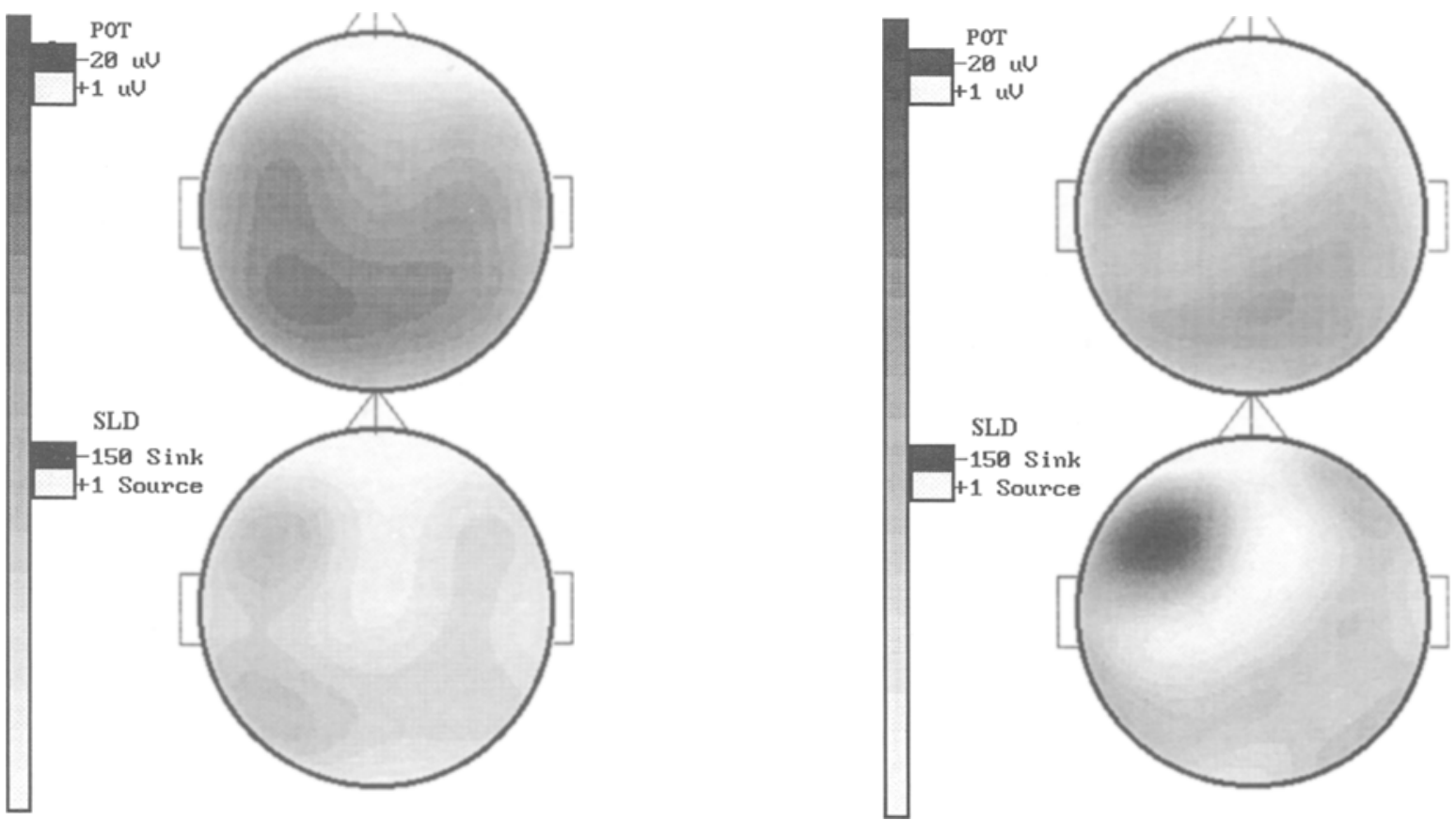

Figure 8. SP and SLD maps during reading aloud. Left: group of women. Right: group of men; note the pronounced activity in the left hemisphere.

\section{Recording Individual Electrode Locations}

Due to the variability of the head geometry, electrode coordinates vary markedly across subjects, no matter what kind of application procedure is used. Data analysis should take this into account because image construction, although specific to the algorithm employed, is sensitive to this variability as follows from the above.

For SLD, for example, Le et al. (1994) reported:

As a signal processing method, the quality of the SLD depends solely upon the quality of the input data. Any perturbation of the measured electrode position $\left(x_{i}, y_{i}, z_{i}\right)$ from the actual position or of the measured potential value $\mathrm{U}_{i}$ at these positions will severely perturb the SLD estimates. This is an inherent problem of the SLD, resulting from the fact that a spatial distribution function is differentiated twice in its parametric space.

The use of a 3-D digitizer for recording individual electrode locations is therefore highly recommended. It helps to significantly reduce signal variance due to interindividual spatial jitter in electrode locations, especially with smaller numbers of recording channels. To eliminate the inconveniences of this time-consuming scanning procedure (head stabilization by bite bar and forehead frame during digitization), we are currently developing a "parallel" 3-D scanning procedure that makes it unnecessary for the subject to keep his or her head immobile for several minutes.

\section{Image Normalization and Data Extraction}

With such techniques as rCBF, SPECT, PET, and fMRI, where the observed signals are inherently linked to spatial aspects of the brain structures, image normalization procedures (e.g., "warping") have necessarily evolved because of interindividual differences in head and brain geometry. With EEG imaging based on realistic head models, where the alignment of EEG activity and 3-D gyral locations will be the essential step, a similar normalization will be necessary. It would be beyond the scope of this article to describe the procedures that have already been developed in the context of metabolically based brain imaging techniques, but their application would greatly enhance EEG/ERP imaging and SPT.

\section{Sample Studies}

In order to illustrate the specific merits of SPT for an electrophysiologically oriented cognitive neuroscience, several studies will be reviewed below. Aside from CNV, $\mathrm{RP}, \mathrm{MMN}$, and $\mathrm{Nd}$ studies, some differently designed experiments pioneered the successful application of SPT for the investigation of mental computation (Rösler \& Heil, 1991; Rösler, Schuhmacher, \& Sojka, 1990; Ruchkin, Johnson, Mahaffey, \& Sutton, 1988), visual monitoring and/or scanning of short-term memory (Horst, Ruchkin, \& Munson, 1987; Looren de Jong, Kok, \& van Rooy, 1987; Wijers, G. Mulder, Okita, \& L. J. M. Mulder, 1989a, 1989b), imagery and mental rotation (Farah \& Peronnet, 1989; Rösler et al., 1990; Wijers, Otten, Feenstra, G. Mulder, \& L. J. M. Mulder, 1989), concept formation (Delisle, Stuss, \& Picton, 1986; M. Lang et al., 1987; Uhl, W. Lang, M. Lang, A. Kornhuber, \& Deecke, 1990 ), and the planning and execution of motor responses (Deecke, Uhl, Spieth, W. Lang, \& M. Lang, 1987; M. Lang 
et al., 1988; W. Lang, Zilch, Koska, Lindinger, \& Deecke, 1989).

When interpolation and mapping techniques were integrated, SPT finally became established as a research procedure comparable to, for example, rCBF monitoring, since essential aspects, such as spatial sampling, variable head size and shape, interpolation algorithm, or the use of the SLD, have been at least taken into consideration.

As an early example, we would like to address two articles by W. Lang, Obrig, Lindinger, Cheyne, and Deecke (1990) and W. Lang, Cheyne, Kristeva, Lindinger, and Deecke (1991). Both papers focus on the functional localization of cortical processes linked to controlled motor activity. To my knowledge, these papers were the first to use sequences of maps to display the time course of the cortical activity distribution during temporally extended cognitive activity. Subjects were asked to perform simple and complex right, left, and bimanual finger movements of their own volition. For example, subjects (musicians) either tapped with their left and right index fingers in synchrony (quavers, 2 against 2) or tapped quavers against triplets ( 2 against 3 ). Either the right or the left index finger started tapping quavers, and, after about $4 \mathrm{sec}$, the other index finger joined in with either quavers (identical or simple rhythm) or triplets (different or com- plex rhythm). The subjects themselves decided when to begin the trials.

The results clearly show cortical areas involved in different motor performances: the early nonlateralized (mesial, fronto-central) and late lateralized (central) component of the RP before movement initiation, the lateralized central activity that accompanied tapping, and a mesial, fronto-central activity that also becomes visible with difficult (controlled) motor behavior.

An even more complex and motor-free cognitive process has been investigated by Rösler and colleagues (Heil, Rösler, \& Henninghausen, 1994). In their study, subjects had to learn new associations between target items and mediators; these experimentally established links were examined in a subsequent run. More precisely, target items were drawings of objects (e.g., dogs, ships, trees, etc.) that were presented in stable links together with one, two, or three mediators (i.e., words, colors, or marked locations in a grid). The mediator words were semantically unrelated to the targets. After learning these associations to a $100 \%$ criterion, subjects were tested in a retrieval run as to whether or not target pairs presented shared a mediator. In order to come up with an answer, subjects needed to reactivate the mediators $(1,2$, or 3 words, colors, or spatial locations) irrespective of whether the answer was "yes" or "no."

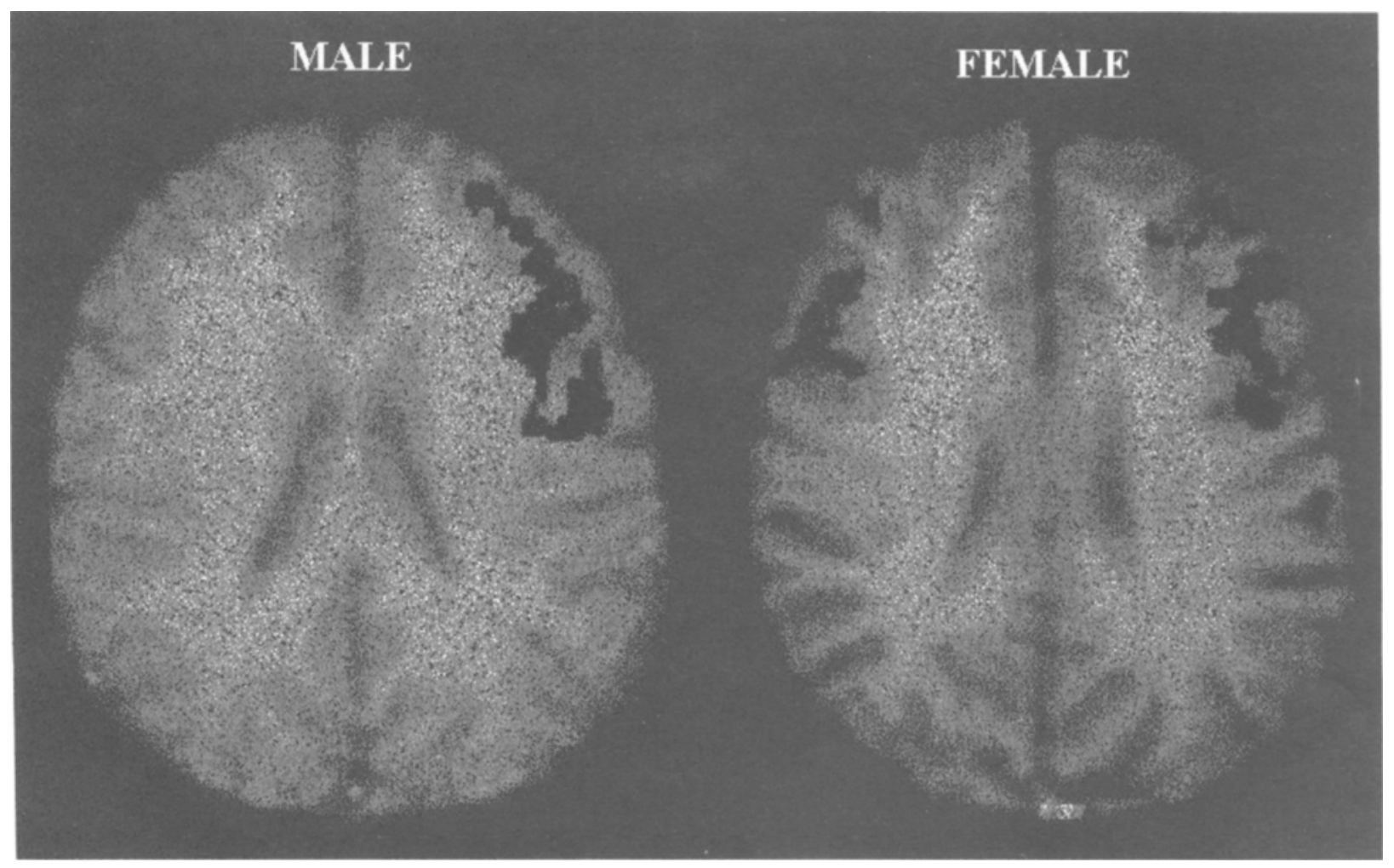

Figure 9. Brain activation patterns during reading, as revealed in $\mathbf{f}$ MRIs, differ in men and women. During phonological coding, men show primarily unilateral activation in the left inferior frontal gyrus (dark areas). In women, phonological processing activates both the left and the right inferior frontal gyri. From "Sex Differences in the Functional Organization of the Brain for Language," by B. Shawitz et al., 1995, Nature, 373, p. 608. Copyright 1995 by Macmillan Journals Ltd. Adapted with permission. 
In this way, different locations of cortical activity for word, color, and spatial stimuli could be identified during retrieval (i.e., frontal negativity with words, parietal with grid locations, and occipital with color mediators; see Figure 4. Additionally, with verbal and spatial mediators, there was a clear positive correlation between task difficulty/complexity (number of mediators) and amount of localized cortical negativity.

Verbal and spatial processing has also been investigated by Vitouch et al. (1997). In this study, subjects (males, right-handed, preselected into groups of good and poor spatializers using the three-dimensional cube test, 3DW; Gittler, 1990) were presented with dichotomous items in two separate experimental runs. In the verbal condition, two semantic relations per trial had to be checked for identity. In the spatial run, pairs of drawings of cubes needed to be checked for possible identity when rotated (see Figure 5).

According to analyses based on item-response theory, these 3DW-derived spatial items have the property of challenging one essentially identical dimension of cognitive ability in all subjects. Validation studies have revealed that the provoked cognitive activity may be labeled mental rotation. Figure 6 summarizes the results.

During verbal processing a fronto-parietal activity was clearly obvious in the left hemisphere that was significantly different from the occipito-parieto-temporal activity during spatial processing. One interesting feature was the higher amount of activity during spatial processing in the case of poor spatializers, relative to good spatializers. This observation is in keeping with PET results. Haier and colleagues also reported a negative correlation between parieto-temporal glucose uptake and performance level (Haier et al., 1988; Haier, Siegel, Tang, Abel, \& Buchsbaum, 1992). This group also demonstrated a reduction in task-specific glucose uptake with training. Such a result could not be replicated in our laboratory when employing a 12-h mental rotation training distributed over a period of 4 weeks (Lamm, 1996). This training did not change the task-specific topography as shown in Figure 6 but it evoked additional frontal activity (compare Figure 7). That may point to training-induced enhancement of executive control of cognitive processing (Posner \& Raichle, 1994).

The last SPT example resembles an fMRI observation. Figure 8 shows the mean cortical activity distributions of a group of male subjects and a group of female subjects during reading aloud. Subjects were asked to read one-line sentences presented on a screen. With each line, subjects had to fixate a dot at the left margin and to start reading at the end of a signal tone. After having read a line, subjects fixated the marker of the next line and waited for the next start signal. The analysis of multichannel cognitively evoked slow potential changes revealed different activity distributions in males and females. In females, activity appears symmetrically distributed; in males, a left hemisphere frontal focus can be seen. This is especially obvious in SLD maps.
Shawitz et al. (1995) observed almost identical sex differences in fMRI scans with phonologic coding, an essential part of the reading process: Males showed asymmetrical activity in the posterior part of the left inferior frontal gyrus, but females had bilateral activity maxima in the same locations (see Figure 9).

\section{Future Perspectives}

All these studies only partly used the potential power of SPT, since, for example, statistical inferences were based only on actually recorded potential values, neglecting variance among recording locations, whereas maps were used merely for illustration. On the other hand, these examples demonstrate the potential merits of SPT for the localization of cortical activity when taking into account the advantage of SLD maps over mere scalp potential distribution (see Figure 8).

EEG and ERP recording needs to be turned into a real imaging procedure, in which the recording of brain potential is only the first step and statistical comparisons use activity measurements at spatially, but preferably anatomically, identified locations. In this context and in view of the promising preliminary SPT results presented, we would like to emphasize what Gevins et al. (1991) stated:

The fact that such a real imaging procedure has not been achieved is not due to an inherent lack of information in EEGs or ERPs, but to a relative lack of commitment of resources. The quantity and quality of information obtainable from EEGs is currently limited by the number of scalp recording sites and the amount and type of numerical computation applied. Since the former is only a matter of habit, and since computing has become so powerful and inexpensive, we feel that it is timely for the imaging capability of EEGs to make a major advance. (p. 125)

\section{REFERENCES}

Bauer, H., Korunka, C., \& Leodolter, M. (1989). Technical requirements for high-quality scalp DC recordings. Electroencephalography \& Clinical Neurophysiology, 72, 545-547.

Bauer, H., Korunka, C., \& Leodolter, M. (1993). Possible glial contribution in the electrogenesis of SPs. In W. C. McCallum \& S. H. Curry (Eds.), Slow potential changes in the human brain (pp. 23-34). New York: Plenum.

Biggins, C., FeIN, G., Raz, J., \& Amir, A. (1991). Artifactually high coherence result from using spherical spline computation of scalp current density. Electroencephalography \& Clinical Neurophysiology, 79, 413-419.

CASPERS, H. (1974). DC potentials recorded directly from the cortex: Preface. In A. Remond (Ed.), Handbook of electroencephalography and clinical neurophysiology (Vol. 10, Part A, pp. 1-87). Amsterdam: Elsevier.

Caspers, H., Speckmann, E.-J., \& Lehmenkühler, A. (1984). Electrogenesis of slow potentials of the brain. In T. Elbert, B. Rockstroh, W. Lutzenberger, \& N. Birbaumer (Eds.), Self-regulation of the brain and behavior (pp. 26-41). Berlin: Springer-Verlag.

CAton, R. (1875). The electric currents of the brain. British Medical Journal, 2,278 .

COles, U.-J. A., \& ORKand, R. K. (1983). Modification of potassium movement through the retina of the drone (Apis mellifera) by glial uptake. Journal of Physiology, 340, 157-174.

Coppola, R. (1990). Topographic mapping of multilead data. In J. W. 
Rohrbaugh, R. Parasuraman, \& R. Johnson, Jr. (Eds.), Event-related brain potentials (pp. 37-43). New York: Oxford University Press.

Cuffin, N. B., \& CoHEN, D. (1979). Comparison of MEG and EEG. Electroencephalography \& Clinical Neurophysiology, 47, 640-644.

Deecke, L., Uhl, F., Spieth, F., Lang, W., \& LanG, M. (1987). Cerebral potentials preceding and accompanying verbal and spatial tasks. ln R. J. Johnson, Jr., J. W. Rohrbaugh, \& R. Parasuraman (Eds.), Current trends in event-related potential research (EEG Suppl. 40, pp. 17-23). Amsterdam: Elsevier.

Delisle, M., Stuss, D. T., \& Picton, T. W. (1986). Event-related potentials to feedback in a concept-formation task. In W. C. McCallum, R. Zappoli, \& F. Denoth (Eds.), Cerebral psychophysiology: Studies in event-related potentials (EEG Suppl. 38, pp. 103-105). Amsterdam: Elsevier.

Dietzel, I., Heinemann, U., Hofmeier, G., \& Lux, H. D. (1989). Relations between slow extracellular potential changes, glial potassium buffering, and electrolyte and cellular volume changes during neural hyperactivity in cat brain. Glia, 2, 25-44.

DOYLE, J. C., \& GEVINS, A. (1986). Spatial filters for event-related brain potentials (Tech. Rep. TR86-001). San Francisco: EEG Systems Laboratory.

Farah, M. J., \& Peronnet, F. (1989). Event-related potentials in the study of mental imagery. Journal of Psychophysiology, 3, 99-109.

FEIN, G., RAZ, J., \& TURETSKY, B. (1991). Brain electrical activity: The promise of new technologies. In S. Zakhari \& E. Witt (Eds.), Imaging in alcohol research (Proceedings of a Workshop on Imaging in Alcohol Research, Wild Dunes, SC, pp. 49-78).

Fletcher, E. M., Kussmaul, C. L., \& Mangun, G. R. (1996). Estimation of interpolation errors in scalp topographic mapping. Electroencephalography \& Clinical Neurophysiology, 98, 422-434.

FrEEMAN, W. (1980). Use of spatial deconvolution to compensate for distortion of EEG by volume conduction. IEEE Transactions on Biomedical Engineering, 27, 421-429.

FUSTER, J. M. (1978). Sustained activation of cortical neurons in stimulusrecognition tasks. In D. A. Otto (Ed.), Multidisciplinary perspectives in event-related brain potential research (pp. 48-50). Washington, DC: U.S. Environmental Protection Agency.

Gevins, A. (1989). Dynamic functional topography of cognitive tasks. Brain Topography, 2, 37-56.

Gevins, A. (1990). Dynamic patterns in multiple lead data. In J. W Rohrbaugh, R. Parasuraman, \& R. Johnson, Jr. (Eds.), Event-related brain potentials (pp. 44-56). New York: Oxford University Press.

Gevins, A., Brickett, P., Costales, B., Le, J., \& Rfutter, B. (1990). Beyond topographic mapping: Towards functional anatomical imaging with 124-channel EEGs and 3-D MRIs. Brain Topography, 3, 53-64.

Gevins, A., Le, J., BRICKeTt, P., Reutter, B., \& Desmond, J. (1991). Seeing through the skull: Advanced EEGs use MRIs to accurately measure cortical activity from the scalp. Brain Topography, 4, 125-131.

Gevins, A., Le, J., Martin, N., Brickett, P., Desmond, J., \& ReutTER, B. (1994). High resolution EEG: 124-channel recording, spatial deblurring and MRI integration methods. Electroencephalography \& Clinical Neurophysiology, 90, 337-358.

GITTLER, G. (1990). Dreidimensionaler Würfeltest (3DW). Ein Raschskalierter Test zur Messung des räumlichen Vorstellungsvermögens. Theoretische Grundlagen und Manual. [The three-dimensional cube test (3DC)]. Weinheim, Germany: Beltz Test.

Haier, R. J., Siegel, B. V., Jr., Nuechterlein, K. H., Hazlett, E., Wu, J. C., Paek, J., Browning, H. L., \& Buchsbaum, M. S. (1988). Cortical glucose metabolic rate correlates of abstract reasoning and attention studied with positron emission tomography. Intelligence, 12, 199-217.

Haier, R. J., Siegel, B. V., JR., Tang, C., Abel, L., \& Buchsbaum, M. S. (1992). Intelligence and changes in regional cerebral glucose metabolic rate following learning. Intelligence, 16, 415-426.

Heil, M., Rösler, F., \& Hennighausen, E. (1994). Dynamics of activation in long-term memory: The retrieval of verbal, pictorial, spatial, and color information. Journal of Experimental Psychology: Learning, Memory, \& Cognition, 20, 185-200.

HJORT, B. (1975). An online transformation of EEG scalp potentials into orthogonal source derivations. Electroencephalography \& Clinical Neurophysiology, 39, 526-530.

HJORT, B. (1980). Source derivation simplifies topographical EEG interpretation. American Journal of EEG Technology, 20, 121-132.

Horst, R. L., Ruchkin, D. S., \& Munson, R. C. (1987). Event-related potential processing negativities related to workload. In R. Johnson, Jr,, J. W. Rohrbaugh, \& R. Parasuraman (Eds.), Current trends in event-related potential research (EEG Suppl. 40, pp. 186-190). Amsterdam: Elsevier.

KATZNELSON, R. (1981). EEG recording, electrode placment and aspects of generator localization. In P. Nunez (Ed.), Electrical fields in the brain (pp. 176-213). New York: Oxford University Press.

KearfotT, R. B., Sidman, R. D., Major, D. J., \& Hill, C. D. (1991). Numerical tests of a method for simulating electrical potentials on the cortical surface. IEEE Transactions on Biomedical Engineering, 38, 294-299.

KETTENMAN, H. (1987). Oligodendrocytes control extracellular potassium by active uptake and spatial buffering. In T. Grisar et al. (Eds.), Biochemistry of glial cells. New York: Pergamon.

Kuffler, S. W., Nicholls, J. G., \& ORKand, R. K. (1966). Physiological properties of glial cells in the central nervous system of amphibia. Journal of Neurophysiology, 29, 768-787.

LAMM, C. (1996). Raumvorstellungstraining und langsame, ereigniskorrelierte Potentials. [Training of spatial cognition and slow potential shifts]. Unpublished master's thesis, University of Vienna.

Lang, M., Lang, W., Uhl, F., Kornhuber, A., Deecke, L., \& KornHUBER, H. H. (1987). Slow negative potential shifts indicating verbal cognitive learning in a concept formation task. Human Neurobiology, 6, 183-190.

LanG, M., Lang, W., Uhl, F, Koska, C., Kornhuber, A., \& Deecke, L. (1988). Negative cortical DC shifts preceding and accompanying simultaneous and sequential finger movements. Experimental Brain Research, 41, 1-9.

Lang, W., Cheyne, D., Kristeva, R., Lindinger, G., \& Deecke, L. (1991). Functional localisation of motor processes in the human cortex. In C. H. M. Brunia, G. Mulder, \& M. N. Verbaten (Eds.), Eventrelated brain research (EEG Suppl. 42, pp. 97-115). Amsterdam: Elsevier.

Lang, W., Obrig, H., Lindinger, G., Cheyne, D., \& Deecke, L. (1990). Supplementary motor area activation while tapping bimanually different rhythms in musicians. Experimental Brain Research, 79, 504-514.

Lang, W., Zilch, O., Koska, C., Lindinger, G., \& Deecke, L. (1989). Negative cortical DC shifts preceding and accompanying simple and complex sequential movements. Experimental Brain Research, 74, 99-104.

LAw, S., \& Nunez, P. (1991). Quantitative representation of the upper surface of the human head. Brain Topography, 3, 365-371.

Law, S., Nunez, P., \& WiJesinghe, R. (1993). High-resolution EEG using spline generated surface Laplacian on spherical and ellipsoidal surfaces. IEEE Transactions on Biomedical Engineering, 40, 145-153.

LE, J., \& Gevins, A. (1993). Method to reduce blur distortion from EEGs using a realistic head model. JEEE Transactions on Biomedical Engineering, 40, 517-528.

Le, J., Menon, V., \& Gevins, A. (1994). Local estimate of surface Laplacian derivation on a realistically shaped scalp surface and its performance on noisy data. Electroencephalography \& Clinical Neurophysiology, 90, 433-441.

LEHMANN, D. (1986). Spatial analysis of EEG and evoked potential data. In F. H. Duffy (Ed.), Topographic mapping of brain electrical activity (pp. 23-61). Boston: Buttersworths.

LoOren de Jong, H., KoK, A., \& van Rooy, J. C. G. M. (1987). Electrophysiological indices of visual selection and memory search in young and old subjects. In R. Johnson, Jr., J. W. Rohrbaugh, \& R. Parasuraman (Eds.), Current trends in event-related potential research (EEG Suppl. 40, pp. 341-349). Amsterdam: Elsevier.

Lutzenberger, W., Elbert, T., \& Rockstroh, B. (1987). A brief tutorial on the implications of volume conduction for the interpretation of the EEG. Journal of Psychophysiology, 1, 81-89. 
Nicholas, P., \& Deloche, G. (1976). Convolution computer processing of the brain electrical image transmission. International Journal of Bio-Medical Computing, 7, 143-159.

NicHoLSON, C. (1980). Dynamics of the brain cell microenvironment Neuroscience Research Program Bulletin, 18, 177-322.

NUNEz, P. (1981). Electrical fields in the brain. New York: Oxford.

NunEz, P. (1987). A method to estimate local skull resistance in living subjects. IEEE Transactions on Biomedical Engineering, 34, 902-904.

NUNEZ, P. (1989). Estimation of large scale neocortical source activity with EEG surface Laplacians. Brain Topography, 2, 141-154.

NunEz, P. (1990). Physical principles and neurophysiological mechanisms underlying event-related potentials. In J. W. Rohrbaugh, R. Parasuraman, \& R. Johnson, Jr. (Eds.), Event-related brain potentials (pp. 19-36). New York: Oxford University Press.

Perrin, F., BerTRAND, O., \& Pernier, J. (1987). Scalp current density mapping: Value and estimation from potential data. IEEE Transactions on Biomedical Engineering, 34, 283-288.

Perrin, F., Pernier, J., Bertrand, O., \& Echallier, J. F. (1989). Spherical splines for scalp potential and current density mapping. Electroencephalography \& Clinical Neurophysiology, 72, 184-187.

Posner, M. I., \& Raichle, M. E. (1994). Images of mind. New York: W. H. Freeman.

Ransom, B. R., Carlini, W. G., \& Connors, B. (1986). Brain extracellular space: Developmental studies in rat optic nerve. In $\mathbf{H}$. F Cserr (Ed.), The neuronal microenvironment (Annals of the New York Academy of Sciences, Vol. 481, pp. 78-105). New York: New York Academy of Sciences.

REBERT, C. S. (1973). A technique for simultaneous measurement of DC and multiple unit responses. Electroencephalography \& Clinical Neurophysiology, 34, 326-328.

Rockstroh, B., Elbert, T., Canavan, A., Lutzenberger, W., \& BirBAUMER, N. (1989). Slow brain potentials and behavior (2nd ed.) Baltimore: Urban \& Schwarzenberg.

RoITBAK, A. I. (1965). Slow negative potentials of the cortex and neuroglia [in Russian]. In V. V. Parin (Ed.), The modern problems of the physiology and pathology of the nervous system (pp. 68-93). Moscow: Meditsina.

RorTBAK, A. I. (1983). Neuroglia: Eigenschaften, Funkionen, Bedeutung. [Neuroglia: Properties, function, importance]. Jena: Gustav Fischer.

Roitbak, A. I., Fanarditan, V. V., MelKonyan, D. S., \& Melkonyan, A. A. (1987). Contribution of glia and neurons to the surface-negative potentials of the cerebral cortex during its electrical stimulation. Neuroscience, 20, 1057-1067.

Rosen, S. C., \& Stamm, J. S. (1969). Cortical steady potential shifts during delayed response performance by monkeys. Electroencephalography \& Clinical Neurophysiology, 27, 684-685.

RösLER, F., \& HeIL, M. (1991). A negative slow wave related to conceptual load which vanishes if the amount of load is increased? A reply to Ruchkin and Johnson. Psychophysiology, 28, 363-364.

Rösler, F., Heil, M., \& Hennighausen, E. (1995). Distinct cortical activation pattems during long-term memory retrieval of verbal, spatial and color information. Joumal of Cognitive Neuroscience, 7, 57-65.

Rösler, F. SCHumacher, G., \& SoIKa, B. (1990). What the brain reveals when it thinks. Event-related potentials during mental rotation and mental arithmetic. German Journal of Psychology, 14, 185203.

Ruchkin, D. S., Johnson, R., JR., Mahaffey, D., \& Sutron, S. (1988). Toward a functional categorization of slow waves. Psychophysiology, 25, 339-353.

Rush, S., \& DrISCOLL, D. A. (1969). EEG electrode sensitivity: An application of reciprocity. IEEE Transactions on Biomedical Engineering, 16, 15-22.

Shawitz, B., Shaywitz, S., Pugh, K., Todd Constable, R., Skudlarski, P., Fulbright, R., Bronen, R., Fletcher, J., ShankWEILER, D., KATZ, L., \& GORE, J. (1995). Sex differences in the functional organization of the brain for language. Nature, 373, 607-609.

Somjen, G. G., \& Trachten Berg, M. (1979). Neuroglia as generators of extracellular current. In E.-J. Speckmann \& H. Caspers (Eds.), Origin of cerebral field potentials (pp. 164-174). Stuttgart: Thieme.

Speckmann, E.-J., Caspers, H., \& Elger, C. E. (1984). Neuronal mechanisms underlying the generation of field potentials. In T. Elbert, B. Rockstroh, W. Lutzenberger, \& N. Birbaumer (Eds.), Self-regulation of the brain and behavior (pp. 9-25). Berlin: Springer-Verlag.

Srinivasan, R., Nunez, P., Tucker, D., Silberstein, R., \& CaDUSCH, P. (1996). Spatial sampling and filtering of EEG with spline Laplacians to estimate cortical potential. Brain Topography, 8, 355-366.

Srinivasan, R., Tucker, D. M., \& Murias, M. (1998). Estimating the spatial Nyquist of the human EEG. Behavior Research Methods, Instruments, \& Computers, 30, 8-19.

Stamm, J. S., \& Rosen, S. C. (1972). Cortical steady potential shifts and anodal polarization during delayed response performance. Acta Neurobiologiae Experimentalis, 32, 193-210.

Svoboda, J., \& SyKova, E. (1991). Extracellular space volume changes in the rat spinal cord produced by nerve stimulation and peripheral injury. Brain Research, 560, 216-224.

SYKOVA, E. (1983). Extracellular potassium accumulation in the central nervous system. Progress in Biophysics \& Molecular Biology, 42, 135-189.

Sykova, E. (1987). Modulation of spinal chord transmission by changes in extracellular $\mathbf{K}+$ activity and extracellular volume. Canadian Journal of Physiology Pharmacology, 65, 1058-1066.

Sykova, E., \& ChVatal, A. (1993). Extracellular ionic and volume changes: The role of glia-neuron interaction. Journal of Chemical Neuroanatomy, 6, 247-260.

Sykova, E., Hansson, E., Rönnbäck, L., \& Nicholson, C. (1998). Glial regulation of the neuronal microenvironment. In P. R. Laming, A. Reichenbach, E. Sykova, H. Bauer, \& G. Hatton (Eds.), Glial cells and their role in behavior (pp. 130-163). New York: Cambridge University Press.

Thickbroom, G., Mastaglia, F., Carroll, W., \& Davies, H. (1984). Source derivation: Application to topographic mapping of visual evoked potentials. Electroencephalography \& Clinical Neurophysiology, 59, 279-285.

TODD, T. W. (1924). Thickness of the male white cranium. Anatomical Record, 27, 245-256.

Tucker, D. (1993). Spatial sampling of head electrical fields: The geodesic sensor net. Electroencephalography \& Clinical Neurophysiology, 87, 154-163.

Uhl, F., Lang, W., Lang, M., Kornhuber, A., \& Deecke, L. (1990). DC potential evidence for bilateral symmetrical frontal activation in non-verbal associative learning. Journal of Psychophysiology, 4, 241-248.

VAUGHAN, H. G., JR., \& AREZzo, J. C. (1988). The neural bases of eventrelated potentials. In T. Picton (Ed.), Human event-related potentials (pp. 45-96). Amsterdam: Elsevier.

Vitouch, O., Bauer, H., Gitrler, G., Leodolter, M., \& LeodolTER, U. (1997). Cortical activity of good and poor spatial test performers during spatial and verbal processing studied with slow potential topography. International Journal of Psychophysiology, 27, 183-199.

WaNG, J., Cohen, L. M., \& Hallett, M. (1989). Scalp topography of somatosensory evoked potentials following electrical stimulation of femoral nerve. Electroencephalography \& Clinical Neurophysiology, 74, 112-123.

WiJers, A. A., Mulder, G., OKitA, T., \& Mulder, L. J. M. (1989a). Attention to color: An analysis of selection, controlled search, and motor activation, using event-related potentials. Psychophysiology, 26, 89-109.

Wijers, A. A., Mulder, G., Okita, T., \& Mulder, L. J. M. (1989b). Event-related potentials during memory search and selective attention to letter size and conjunctions of letter size and color. Psychophysiology, 26, 529-547.

Wijers, A. A., Otten, L. J., Feenstra, S., Mulder, G., \& Mulder, L. J. M. (1989). Brain potentials during selective attention, memory search, and mental rotation. Psychophysiology, 26, 452-467. 